\title{
Determinants of Cereal Crops Productivity of Rural Ethiopia: A Case Study of Rural Smallholder Farmers of Kecha Birra Woreda in Kambata Zone, Ethiopia
}

\author{
Takele Ayele $^{1} \quad$ Negese Tamirat ${ }^{2}$ \\ 1.Corresponding Authors: Takele Ayele, Department of Economics, Jimma University, Jimma, Ethiopia \\ 2.Negese Tamirat: Department of Economics, Jimma University, Jimma, Ethiopia
}

\begin{abstract}
The study was conducted in Kecha Birra district, Kambata Zone, Southern Nation, Nationality and People Region (SNNR) toassess the determinants of cereal crop productivity in Kecha Birra Woreda. Agriculture plays prominent role in the process of economic development for a country; without achieving substantial increase in agricultural production, no country has moved to take off stage of economic development. 22 cereal crop producing kebeles among the 5 cereal crop producing kebeles were selected and a total of 333 selected households were interviewed to generate primary data. Descriptive statistics and OLS regression model were employed to determine factors that influence the cereal crop productivity of farmers. A sum of eleven independent variables for the OLS regression model was used, out of which seven variables were found to significantly influence the cereal crop productivity of farmers. These are: education level household head, access credit service, access to extension service, family size of household head, use of fertilizer, use recommended agricultural inputs and improved seed. The study recommends that any effort in promoting improved cereal crop productivity should consider the social, economic, institutional and psychological characteristics for better enhancing improved cereal crop productivity.
\end{abstract}

Keywords: Cereal Crop, Kecha Birra Woreda, OLS regression model, Productivity, Ethiopia

DOI: $10.7176 / \mathrm{JPID} / 52-04$

Publication date: January $31^{\text {st }} 2020$

\section{Introduction}

In Less Developed Countries (LDCs) in general and Sub-Saharan Africa (SSA) in particular, economic policy highly depended on agriculture. Poverty reduction and income growth can mainly be achieved by agricultural growth. It creates spillover effects to the remaining sectors [1]. However, production and productivity of the agricultural sector in SSA is low due to low technological adoption and techniques among others [2\&3]. The situation in Ethiopia is not any different. Problem such as low technology adoption, low use of recommended farm inputs, broadcast farming and rain-fall are the prime bottlenecks behind the poor performance of the sector [4].

In Ethiopia about $85 \%$ of total population is live in rural areas and agriculture is their main source of their livelihood. Agriculture becomes the second most dominant next to service sector of the country economy. The sector accounts for about 50\% of the Gross Domestic Product (GDP), 90\% of the total export revenue, 85\% employment of the country's labor force and accounts $70 \%$ of raw materials requirement of the country's industries, which is important four countries sustainable development [5]. Consequently, it has been the core element of the country's Agriculture Development Led Industrialization (ADLI) strategy for many years [6]. Agriculture sector is rainfall dependent; timing of rainfall is of critical importance. The right amount of rain at the right time is far more important than the use of fertilizer, improved seeds, agrochemical or irrigation in increasing cereal crop productivity. The main goal of agricultural policy is not only achieving sustainable increase in agricultural production and productivity of smallholder farmers, but also accelerates agricultural commercialization and agro-industrial development in the country.

In Ethiopia cereal crop production is dominated by rural smallholder farm households. The yield of cereal is very low because of low adoption of improved agricultural technologies, weather fluctuation, climatic change, rapid population growth, difference in land size holding and livestock. Due to this reason cereal crop productivity in Ethiopia has not been able to satisfy the food requirement of the people [7]. In addition, the productivity of cereal crop in Ethiopia was severely restricted due to many recurrent disasters: these are; flood, lack of diversity of items and due to weak subsistence agriculture economy. According to the most recent report of Ethiopian economic association, gaining in the yield level in the rural farm areas over the past few years for most cereal crops has not been able to increase average yield for most countries as a whole [8]. Even though, agriculture is the crucial sector in the national economy, its production and productivity is unsatisfactory. So, an important way to increase cereal crop productivity is that reducing constraints of agriculture. These constraints reduced through diffusion of improved seed, land management practice and training farmers [9].

However, a few studies have been conducted focusing on the different dimensions of rural smallholder farm 
households in Ethiopia, particularly, in Kambata Zone. However, most of these studies have focused on marketing and were limited to a specific area and production aspects. Systematic and adequate information on the determinants of cereal crop productivity were not well identified. Further, in the study area there is no empirical study conducted on the determinants of cereal crop productivity of rural smallholder farm households. Therefore, this study was conducted to assess determinants of cereal crop productivity of rural smallholder farm households. Specifically, this study was conducted to identify rural household crop yield and indicators in Smallholder rural areas of the Kambata Zone, to identify the key determinants of cereal crop productivity among rural smallholder farm households along with other socio-economic factors in increasing smallholder rural farm household cereal crop productivity.

Several determinants of cereal crop productivity study findings have pointed to the fact that the agricultural cereal crop productivity cab be influenced by different factors. Several productivity research findings have pointed to the fact that[10] in Nigeria using the ordinary least square method (OLS) who found that farm size, fertilizer and hired labor were significantly influence cereal crop productivity of rural smallholder farm households. The study conducted by [11] in Ethiopia showed that the cereal crop productivity by applying the ordinary least square method (OLS), cereal crop productivity significantly influenced by improved seed and fertilizer. A study conducted by [12] reveals that cereal crop productivity of rural smallholder farm households significantly influenced by fertilizer and farm size using multiple linear regression method. By using the ordinary least square method cereal crop productivity significantly influenced improved seed, farm size, educational level and age of households [13]. An empirical study carried out by [14], showed that fertilizer significantly determines cereal crop production and productivity. [15] Conducted a study on impact of various farm inputs on cereal crop production of peasant farm sector in Ethiopia, by applying seemingly unrelated regression estimation (SURE).The study found that land, labor and chemical fertilizers. The study taken by [14],showed that fertilizer significantly determines cereal crop production. [15] employs a Cobb -Douglas production function to estimate the impact of various farm inputs on cereal crop production of peasant farm sector in Ethiopia and the production function is estimated for the major food crops, teff, wheat, barley, maize, and sorghum, using seemingly unrelated regression estimation(SURE). On average, about 90 per cent of crop production is explained by the two major traditional inputs, land and labor. Less than 10 per cent of output is explained by chemical fertilizers significant on cereal crop production and productivity on rural smallholder farm households.

\section{Methods}

\subsection{Description of the Study Area}

The study was conducted in Kecha Birra Woreda, Kambata Zone, Southern Nations, Nationalities and Peoples Regional (SNNPR), Ethiopia. Kecha Birra Woreda is located in South Nations, Nationalities, People's Region (SNNPR), in the South West central part of Ethiopia about a distance of $282 \mathrm{~km}$ south of Addis Ababa. The total population of the Woreda is 113,687 , of which 55,827 is male and 57,860is female.

\subsection{Sampling Techniques}

The study applied both non-probability and probability sampling techniques to select the sample from a given population. Take into account the resource available, from 22 cereal crop producing rural kebeles of Kecha Birra Woreda; 5 kebeles (Awaye, Gamasha, Ashira, Buge, and Laada) were selected based on their agro-ecological zone compared to the remaining kebeles of the Kecha Birra Woreda. The sample size was determined based on the simplified formula given by [16]. Where $\mathrm{n}=$ the sample size, $\mathrm{N}=$ the population size, and $\mathrm{e}=$ the level of precision. $\mathrm{N}=$ the total number of households in the selected Kebeles (2001HHS), and $\mathrm{e}=$ acceptable error margin 5\%. Based in this, the required sample size was determined as follows.

$$
\mathrm{n}=\frac{\mathrm{N}}{1+\mathrm{N}\left(\mathrm{e}^{2}\right)}=\frac{2001}{1+0.05^{*} 0.05^{*}(2001)}=334
$$

\begin{tabular}{|c|c|c|}
\hline Kebele & Number of households $\left(\mathrm{N}_{\mathrm{i}}\right)$ & Total Sample $\left(\mathrm{n}_{\mathrm{i}}\right)$ \\
\hline Awaye(Kebele 1$)$ & 420 & 70 \\
\hline Gamasha(Kebele 2$)$ & 415 & 69 \\
\hline Ashira(Kebele 3$)$ & 400 & 67 \\
\hline Buge(Kebele 4$)$ & 396 & 66 \\
\hline Laada $\left(\right.$ Kebele $\left._{5}\right)$ & 370 & 62 \\
\hline Total & 4000 & 334 \\
\hline
\end{tabular}

Table 12: Distribution of sample size by kebele

$\mathbf{n}_{\mathbf{i}}=$ total number of households selected from kebele I $(\mathrm{I}=1,2,3,4,5) ; \mathbf{N}_{\mathbf{i}}=$ total number of households in kebele i. 


\subsection{Data Collection}

The data for study was collected from both primary and secondary sources. Cross-sectional data was collected from the survey of randomly selected smallholder rural farm households. For the primary data collection, specifically designed and pre- tested questionnaire based on the objective of the study, and trained data enumerators was used. The questionnaires schedule was tested at 18 randomly selected farm households in the study area. Both quantitative and qualitative information were collected. The data collection included households' demographic, socioeconomic and environmental characteristics (education level household head, access credit service, access to extension service, family size of household head, use of fertilizer, use recommended agricultural inputs and improved seed).Secondary information like population number, agricultural inputs and outputs, farm use pattern, rainfall amounts (annual mean and cropping season), temperature and agroecology, etc were also collected. The survey was carried out in the months of May and June 2018

\subsection{Data Analysis Method}

The study employed both descriptive and econometric methods for data analysis. Accordingly, descriptive statistics were used to provide an overview of the overall data. In addition, inferential statistics (such as chisquare and t-tests) were employed to provide further insights on factors affecting rural smallholder farm household cereal crop productivity. Specifically, we use chi-square tests for identifying qualitative factors affecting rural smallholder farm households' cereal crop productivity whereas t-test selected quantitative factors. Ordinary least square (OLS) estimation technique was applied assess the determinants of the cereal crop productivity [17].The cereal crops productivity model includes these explanatory variables in the form of multiple linear regression function:

$\mathrm{CCP}=\mathrm{F}$ (imsd, fams, fe, edu, fs, age, sex, cr, ir, ftc, uri, pes)

$\mathrm{LnCCP}=\beta_{0}+\beta_{1}$ imsd $+\beta_{2}$ fams $+\beta_{3}$ fe $+\beta_{4}$ edu $+\beta_{5}$ fs $+\beta_{6}$ age $+\beta_{7} \mathrm{sex}+\beta 8 \mathrm{cr}+\beta_{9} \mathrm{ir}+\beta_{10} \mathrm{ftc}+$

$\beta_{11}$ uri $+\beta_{12}$ pes $+\mathrm{U}_{\mathrm{i}}$

Where: CCP is cereal crop productivity, imsd is improved seed, fams is farm size, fe is fertilizer, eduis education level of household, fsis family size, age is age of households, sex is sex of household, cr is credit access, ir is irrigation, $\mathrm{B}_{0}$ is constant term, $\mathrm{B}_{\mathrm{i}}$ is coefficient of explanatory variables, ftc is farmers training center, uri is recommended agricultural inputs, pes is participation of extension access, $U_{i}$ is error term (residual term) and $\mathrm{Ln}=$ logarithmic indicator.

\section{Results and Discussion}

\subsection{Respondents Background}

The very majority of the respondents were headed by males $(79 \%)$ and the remaining about $(21 \%)$ of the sample households were headed by females. This is atypical representative of developing countries where male headship is dominant. About $65 \%$ of the respondents were literates; this figure is greater than the national figure for adult literacy $(36 \%)$ indicating that the area is better off in terms of education. As regard to the landholding of the sample households ranges from 0.75 ha to 3 ha with an average figure of 1.800 ha. The average livestock (including cattle, sheep, goats, pack animals, and poultry) was $10.66 \mathrm{TLU}$ with the minimum and the maximum holdings of 2.9 TLU and 17.2TLU respectively. About $74 \%$ had access to institutional credit where as $26 \%$ respondent does not get enough credit access. $70 \%$ of respondents cannot use irrigation activities and $30 \%$ of the respondents use the irrigation. This implies that the irrigation activities are not well adopted by the farmers in the study area.

\subsection{Main factors that affecting cereal crop productivity}

Education level of household heads: this variable is positive relationship with cereal crop productivity and significant at $5 \%$ probability level. Marginal effect is 0.230 (Table 5), that implies the being other things constant, as year of schooling of household head increased by one, the probability of household being cereal crop producer increase by $3 \%$. Possible explanation is education helps household to increase productivity through promoting awareness on possible advantage of modernizing agriculture and on working efficiency, diversify income, adopting new

Technology which are used to improve cereal crop productivity and information from development agents. Therefore, educated is better to enhancing cereal crop productivity than illiterate one.

Education level of household head: this variable is positive relationship with cereal crop productivity and significant at $5 \%$ probability level. Marginal effect is 0.235 (Table 2), that implies the being other things constant, as year of schooling of household head increased by one, the probability of household being cereal crop productivity increase by $23.5 \%$. Possible explanation is education helps household to increase productivity through promoting awareness on possible advantage of modernizing agriculture and on working efficiency, diversify income, adopting new technology which are used to improve cereal crop productivity and information 
from development agents. Therefore, educated is better to participate in cereal crop productivity than illiterate one.

Use of credit service: this variable is positively related withcereal crop productivity and significant at $5 \%$ probability level. Its odds ratio is 0.425 (Table 2), The implication is that the result is expected since use of credit service is major source of income for agricultural input expenditure in the rural area, hence a household heads who got credit is about 0.5 times more likely participate in cereal crop productivity as compared to household heads who did not get credit. Small farm household heads who have the opportunity of getting credit for agricultural inputs, more participate than those who have no access. The possible explanation is that household heads who got credit; they would use cereal crop productivity more easily to enhance households' cereal crop yields.

Access to extension services: it is positively related with cereal crop productivity. This variable is significant at $10 \%$ probability level (table 2). Farmers need to be equipped with knowledge and skill about specific technology to be effective in agricultural production. The marginal effect of this variable is $(0.321)$ reveals that keeping other factor constant, a unit increase in access to extension services increase the probability of cereal crop productivity by $32.1 \%$ (table 2 ).

Fertilizer: it is positively related with cereal crop productivity. This variable is significant at $1 \%$ probability level (table 5). Its odds ratio is 2.762 (Table 2), The implication is that the result is hence a rural household heads who use fertilizer is about 3 times more likely participate in cereal crop productivity as compared to household heads who did not use fertilizer. Small farm household heads who have the opportunity of using fertilizer for agricultural inputs, more participate than those who have no access to fertilizer.

Family size of household head: this variable is significant at $5 \%$ of significance level in cereal crop productivity (table 2$)$. The marginal effect $(0.084)$ also reveals keeping all other explanatory variables constant, a $1 \%$ increases in family size increases household probability of cereal crop production and productivity by $8.4 \%$. This suggests that family size is among the major variable in influencing decisions of households to participate in cereal crop productivity.

Use of recommended agricultural inputs: it is positively related with cereal crop productivity. This variable is significant at $1 \%$ probability level (table 5). Its odds ratio is 0.389 (Table 2), The implication is that the result is hence a rural household heads who use recommended agricultural inputs is about 0.5 times more likely participate in cereal crop productivity as compared to household heads who did not use recommended agricultural inputs. Small farm household heads who have the opportunity of using recommended agricultural inputs for agricultural inputs, more participate than those who have no access to recommended agricultural inputs.

Improved seed: it is positively related with cereal crop productivity. This variable is significant at $5 \%$ probability level (table 5). Its odds ratio is 1.472 (Table 2), The implication is that the result is hence a rural household heads who use improved seed is about 1.5 times more likely participate in cereal crop productivity as compared to household heads who did not use improved seed. Small farm household heads who have the opportunity of using improved seed for agricultural inputs, more participate than those who have no access to improved seed.

Table 2: Determinants of cereal crop productivity

\begin{tabular}{|c|c|c|c|c|}
\hline Variable & $\begin{array}{l}\text { Robust } \\
\text { Coefficient }\end{array}$ & $\begin{array}{l}\text { Odds } \\
\text { Ratio }\end{array}$ & $\mathbf{P}>|\mathbf{Z}|$ & Marginal effect \\
\hline$\overline{\text { Age }}$ & -.0 .3171265 & 1.245 & 0.434 & -0.147 \\
\hline Sex & 0.434432 & 1.756 & 0.245 & 0.134 \\
\hline Edu & $2.632238^{* *}$ & 0.530 & 0.017 & 0.230 \\
\hline cr & $2.542234^{* *}$ & 0.425 & 0.012 & 0.235 \\
\hline fams & $0.4248332^{* *}$ & 1.472 & 0.032 & 0.084 \\
\hline aft & 0.1534501 & 1.162 & 0.720 & 0.372 \\
\hline uri & $1.720388^{* * *}$ & 0.389 & 0.007 & 0.123 \\
\hline imsd & $0.626750^{* *}$ & 1.872 & 0.035 & 0.040 \\
\hline ir & 0.4171265 & 1.235 & 0.457 & 0.037 \\
\hline Pes & $0.8382332^{* * *}$ & 2.455 & 0.004 & 0.321 \\
\hline fe & $0.5337838^{* * *}$ & 2.762 & 0.008 & 0.231 \\
\hline Cons & 0.0000353 & 1.859443 & $0.000^{* * *}$ & \\
\hline
\end{tabular}

Source: own computation based on data (2018).

Obs $=364$ Total No. of Independent Variables $=12 \quad{ }^{* * *} \mathrm{P}<0.01,{ }^{* *} \mathrm{P}<0.05 \quad$ and ${ }^{*} \mathrm{P}<0.10$

\section{Conclusion and Implication}

The objective of this study was to evaluate the factor that affects cereal crop productivity. Ordinary least square (OLS) estimation and cross-sectional survey data were used to attain the objective of the study. The study 
employed cross sectional household level data collected in 2017/2018 cropping season from 333 sample farming households. Themain factors affecting cereal crop productivity are education level household head, access credit service, access to extension service, family size of household head, use of fertilizer, use recommended agricultural inputs and improved seed. Therefore, it is used to scaling up the best cereal crop productivity and practices to the farmers can be considered as one option while introducing new agricultural practices and technologies is another option.

Understanding the factors that hinder cereal crop productivity is essential in planning and executing technology related programs for meeting the challenges of cereal crop production in our country. Therefore, to enhance cereal crop productivity by farmers, it's important for policy makers and planners of cereal crop producer to understand farmers need as well as their ability to cereal crop productivity in order to come up with technology that will suit them. It is better to encourage cereal crop production because the results of this study signified that application of agricultural technology increase substantially both the productivity and income of farmers.

Cereal crop productivity involves the use of different practices, which require knowledge, and skill of application and management. Education was found to have a strong relation with the cereal crop production as it enhances cereal crop yields. Therefore, due emphasis has to be given towards strengthening rural farmer's education at different levels for small farm households using farmers training centers. Increasing the number of cooperatives organization in the rural area in which the farmers will be able to get credit are basis in enhancing the cereal crop production. Further, it is apparent from the study that if farmers get credit more easily, they would use cereal crop production to enhance cereal crop yields. Thus, the credit facility should target poor farmers especially those who were not enhancing cereal crop productivity due to lack of operating capital. This may encourage the farmers to do commercial farming practice in which they can build their asset to implement the cereal crop production technologyon their farms.

The agricultural research and extension activities need to consider additional agronomic practices along with the cereal crop productivity method in order to increase cereal crop production, and for the successful promotion, adoption and scaling up of good agronomic practices and extension should contact farmers individually as well as in group to be awarded in terms of cereal crop productivity is suitable to improve household production. Fertilizer and improved seed in agricultural sectors still remains critically important. Therefore, local government with together regional should supply fertilizer and improved seed on the time for farmers through creating awareness on recommended amounts. Fertilizer utilization is important in order to increase their cereal crop productivity and improve livelihoods of smallholder's farmers.

\section{References}

1. World Bank (2014). Ethiopia poverty Assessment. Document of the WB for official use only.

2. Abraham B, Araya H, Berhe T, Edwards S, Gujja B, Khadka R, Sen D, Koma Y, Sharif A, and Styger E. (2014). The system of crop intensification: Reports from the field on Improving agricultural production, food security, and resilience to climate change for multiple crops. Addis Ababa, Ethiopia.

3. Gashaw T, Alan B, Nicholas M, and Tanguy B. (2014). The impact of the use of new technologies on farmers wheat yield in Ethiopia. International Food Policy Research Institute (IFPRI). Washington.

4. Lulit M, Ermias E, and Zelalem H, (2012). Public investment in irrigation and training for agriculture-Led development: a CGE approach for Ethiopia. Addis Ababa, Ethiopia.

5. MoFED. (2012). Ethiopian's progress towards eradicating poverty: An interim report on poverty analysis Study. Addis Ababa, Ethiopia.

6. ATA. (2013). Results of 2012 New Tef Technologies Demonstration Trials Draft Report VF. Addis Ababa, Ethiopia. $34 \mathrm{p}$.

7. Hailu, B. (2008). Adoption of improved teff and wheat production technologies in crop livestock mixed systems in northern and western Shewa Zones of Ethiopia. PhD Thesis, Faculty of Natural \& Agricultural Science, University of Pretoria.

8. EEA. (2009). Report on the Ethiopian Economy. Volume VII. 2007/08, Ethiopian Economics Association. Addis Ababa, Ethiopia.

9. CSA. (2000). Report on Area and Production for Major Crops, Ethiopian Agricultural Sample Survey (1999/2000 (1992 E.C.)), Statistical Bulletin 227, Central Statistical Authority (CSA), Addis Ababa, Ethiopia.

10. Iheanacho A, Amaza P and Bila Y. (2006). Identification of Factors that Influence Technical Efficiency of Food Crop Production in West Africa: Empirical Evidence from Borno State, Nigeria. Journal of Agriculture and Rural Development in the Tropics 107 (2). 139 - 147.

11. Belay K. (2003). Agricultural extension in Ethiopia: The Case of participatory demonstration and training extension system. Journal of Social Development in Africa; Harare, 18(1).

12. Rebecca. (2011). Factors affecting the adoption of agricultural innovations on underutilized cereals: The case of Millet among the smallholder farmers in Kenya. African Journal of Agricultural Research Vol. 13. 
13. Asfaw A \& Admassie A. (2004). The role of education on the adoption of chemical fertilizer under different socio-economic environments in Ethiopia. Agricultural Economics, 30, 215-228.

14. Alejandro. (2014). Fertilizer adoption in Ethiopian cereal production: Journal of Development and Agricultural Economics Vol. 6.

15. Yao. (1996). Determinants of cereal crops productivty of peasnt farm sector in Ethiopia . Journal of International Development : Vol. 8 No. 1 69-82.

16. Yamane, T. (1967). Statistics, an Introductory Analysis, 2nd Ed., New York: Harper and Row.

17. Koutsoyiannis. (1977). Theory of Econometrics: An Introductory Exposition of Econometric Methods. ELBS, Macmillan Hampshire. 